\section{Proliferating Subjectivities and the New Media}

\author{
Ray Misson
}

B eing asked to be a respondent to an issue of a journal causes one to wonder about the editorial logic. It could mean that one is an expert in the field, or that the editors know one is likely to make all the contributors feel good by applauding the collection of articles mindlessly, or that they assume you will do your usual stuff and so provide an interesting complement to what the articles present. Since I am patently not an expert in the field, I hope in this case that it is the last of these options.

Without being mindless, it can safely be said that this is an interesting collection of articles and raises some important issues. It is refreshingly free of triumphalist new-age rhetoric that there is now a new universal order brought about by computers, and that the like of what we see on our computer screens has never been seen before. While not downplaying the radical newness, the authors generally acknowledge the textual forbears: Andrew Burn reminds us that texts as early as Frank Baum's Wizard of $\mathrm{Oz}$ triggered the merchandising of a broad formation of surrounding texts in different modes; Valerie Walkerdine relates video games to earlier masculinist narratives, particularly the western (although surely that is too narrowly proscribed a range of progenitor texts: what about adventure comic, dungeons and dragons, etc?); Margaret Mackey notes various ways in which digital and print texts have influenced each other; Ann McGuire interestingly looks at The Sims in relation to the long and honourable tradition of utopian texts; and John Stephens and Mio Bryce discover one of the oldest stories of all being told in manga cyborg narratives.

There are several themes that are worth drawing out of the articles that suggest what is genuinely new about literacy practices involving ICTs, and which the articles show raise significant questions. These can be grouped around the themes of convergence, subject positioning, and critical stances.

First of all, convergence. Convergence was a very popular term a few years ago, referring to the way in which digital electronic devices would all have multiple functions: every mobile phone an entertainment centre, every computer its own home office. This has happened to an extent, but it could also be argued that it hasn't happened as much as was expected. Rather, along with the convergence has gone a great degree of proliferation, the same material becoming

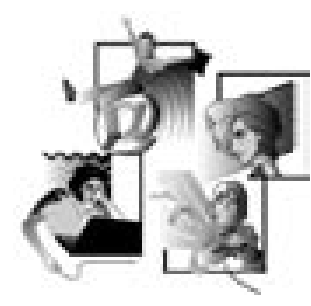

available in different technologies, or, more often, different technologies (including print) being utilised to mediate different aspects of a single product. The convergence is in the content, or rather, the point of convergence is us, the users of the technology, not so much the technology itself. The striking thing is how easily not only young people but most of us now move between technologies to access information, entertainment and communication. Margaret Mackey looks at this phenomenon broadly. Of particular interest are the case studies of Seth and Drew, two young men in their twenties who move seamlessly between print (books, liner notes, magazines, etc), film, TV, DVD, CD, the internet and social interactions to follow through their interests. There is a fluid movement between the media that suggests whether a text is print or digital, visual/aural or linguistic really doesn't matter particularly. Much of the work on multiliteracies seems predicated on the notion that ICTs require a new kind of literacy to be learnt and taught. It may be that literacy is still just about decoding visual and verbal text, as it always has been, and the (multi)media do not make much difference at all. What is new is the sheer availability of different kinds of texts, and the opportunity to move so effortlessly between them.

Mackey goes on to look at the ways in which text producers are capitalising on this fluidity by creating multimedia texts, and how there has been a washback effect on print publishing from texts in other media, because of the ways in which images from TV and the movies influence our visualisation of verbal narratives, and also because of the expectations of texts that have been built up by other media. Andrew Burn picks up the theme of a formation of texts in different media around the same content by examining young people's perceptions of the same incident in a Harry Potter novel, film and video game. Again one is struck by how comfortable the young people seem with the three different media (whether they like the particular example or not), and how sensibly they discuss the differences between them. They seem to be perfectly at ease in moving from one to the other, and to have internalised thoroughly the different generic understandings on which they are built. This is not necessarily at a conscious level: it does seem pretty much naturalised, a matter of the features being what one would expect of a video game or a movie. 
An interesting question that Burn doesn't foreground is what the young people in the study see as the relationship between the three different versions in terms of their understanding of Harry Potter. Will the 'real' Harry Potter please stand up? The book undoubtedly has the benefit of being 'the original'; the film has the benefit of immediacy; the video game has the benefit of interactivity (although, as we will discuss in a minute, most of them say that the interactivity doesn't make them feel closer to Harry Potter). They seem to be quite comfortable having three different versions of the character, with different kinds of 'authenticity', and feel no need to consider one 'truer' than the other. People have always accepted different versions of the same character, of course - how many Electras or Cleopatras have there been? - but there is perhaps something new here in that these Harry Potter texts are so closely related, and are ostensibly presenting not alternative versions but exactly the same character in different refractions. One would not want to press the notion too far, but there does seem to be a postmodern acceptance of multiplicity, a stronger sense of the character as textual construct, and less sense of there being a reality to which the various proliferating versions approximate.

We are moving on here to the question of subjectivity, the kind of person being created through interactions with material on a topic in a range of media and with multimodal texts. It is not surprising that much of the work around this should focus on video games, and, since video games at least began as a predominantly masculine pursuit, on the question of gender.

Three of the four participants in the Burn's study did not feel that the interactivity of the Harry Potter video game led them to identify more closely with the character, even though, in a sense, they were acting for him. Rather, it turned the character into an object, making him something to be manipulated. The excitement, the 'adrenalin thrill' as one of the students called it, came from playing the game, not from thinking about Harry's feelings. How different texts in the different media position their readers/users is a fundamental question if one is interested in the textual creation of subjectivity, and one of the valuable aspects of Burn's article is that he does ask questions about the different ways in which the three texts position the reader/viewer/gamer. People may now move easily from one medium to another in pursuit of their interests, though it is not just different information that they pick up in each medium about different aspects of their topic but a different relationship to the material and a different subjectivity.

Valerie Walkerdine is centrally concerned with questions of subjectivity and she too looks at the way the experience of game playing is positioning the player. The argument that the games are basically masculinist in their adventure content is not something many would contest. However, Walkerdine makes an interesting move beyond this, in that she considers the way in which the actual experience of playing the game affects the achievement of masculinity in particularising it: the skill is not physical action (as for the heroes represented in the games) but rather cognitive and strategic and based on intensive practice. It produces 'the rational subject, the subject of calculating mastery ... the hero as programmer'. Walkerdine's argument is that this is fundamental to achieving and managing masculinity for boys, but that girls are placed in the contradictory position of having to manage and achieve both these masculine qualities and the traditional qualities of femininity. Her subsequent discussion of various groups of girls playing video games is actually most interesting as a demonstration not of the creation of particular kinds of subjectivity through the games but of social negotiation and positioning around the group playing of games. It is a pity that data on the actual effect on the solo player of how they are positioned by the game is so hard to access. Still, the discussion serves to remind us that video games are lodged in a social world, and subjectivity is always situated even as it is constructed. The difficult question is how much one might want to intervene in the particular work of gender construction being done by a game and, if one does, how that can best be achieved.

I think it is important not to conflate the subject matter and the technology. Walkerdine seems inclined to argue not only that the subject matter of adventure games is masculinist, but the video game technology itself is inherently so. Katherine Blashki I suspect would agree, since she sees the educational use of video-game technology as particularly valuable in engaging boys in learning. There are major questions that need to be worked through here. If video game technology is in fact inherently constructive of a particular view of 
masculinity, do we want to proliferate its use, thus excluding girls and firming up the gender divide? Is it really the case that the technology cannot be utilised in ways that are equally engaging to girls and equally supportive of their identity work, and so help with their learning?

I strongly suspect that James Paul Gee, whose book What Video Games have to Teach us About Learning and Literacy is reviewed by Cal Durrant, would argue that the technology is equally available to girls, since it is based on inherently sound, and presumably non-gendered, learning principles. His overall point that video games are necessarily predicated on powerful learning principles is well-argued, and the principles he teases out are unquestionably valuable. The book, however, does very nearly come to grief on this issue of the relationship between subject matter and technology. For much of the book, he brackets off the game content, and so you have such things as him revelling in his game existence as a pickpocketing Half Elf. I have no objection to Half Elves, and it might even be fun to be a pickpocket in a game world, but, if it is important not to conflate the subject matter and the technology, it is equally important not to treat them as if they have absolutely nothing to do with each other.

Which brings us to the last area, that of critical stances that might need to be taken. The article by Ann McGuire on The Sims, and the one by John Stephens and Mio Bryce on Manga both provide evidence that deconstructive critical work is just as significant as it ever was. Ann McGuire reminds us that while a computer game might seem to offer us almost unlimited opportunities for free action, our possibilities are actually very tightly constrained. Andrew Burn also points out that Harry has only six possible moves in the Harry Potter video game, although he argues that this is enough to give us a considerable sense of agency. Ann McGuire might argue that it is precisely that sense of agency that is so worrying. The possibilities open to us are not just technically constrained but the constraints grow out of the cultural context and so are profoundly ideological. The Sims seems to give us the opportunity to create and recreate families with a wealth of difference, but the personality traits the characters are to portray are limited to five (all of them positive and fairly inane), their needs are limited to eight (again nothing more confronting than "bladder") and the game is constructed to place value on particular things, such as the purchase of commodities. McGuire's exposition shows how thoroughly imbued with the ideology of late capitalism the game is, and how easily and seductively it can align us with those values by making us want to succeed in the game. Our seeming freedom of choice in the moves we make in the game masks the interpellation into the game's values.

Stephens and Bryce trace the persistence of traditional stories and traditional values in manga narratives about relationships between human boys and female mechanoids. The narratives, for all their cyborgian contemporaneity, reach ideological closure in the assertion of the (literally) humanising power of love. These manga have, for western readers, a double strangeness of course, a cultural one, as well as being set in a future world where humans and machines can be virtually indistinguishable. Again the need for critical analysis of the ways in which the strangeness is recuperated into the commonest, most 'universal' contemporary belief of all — all you need is love - becomes more and more apparent as the article goes on.

The advent of new media has provided many areas for research. Perhaps most urgent of all is sensible research into how our subjectivity is being constructed and reconstructed by the ways in which we shift between endlessly proliferating texts in diverse media, all of which are positioning us in particular ways. Such research is basic to our ability to understand what we are being asked to buy ideologically and allowing us to gain critical control of our textual worlds.

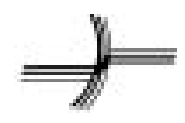

\section{BIOGRAPHICAL NOTE}

Associate Professor Ray Misson is Head of the Department of Language, Literacy and Arts Education and Deputy Dean of the Faculty of Education at the University of Melbourne. His main area of interest centres on the significance of cultural studies for classroom practice, and he has written extensively on popular culture, critical literacy, narrative, sexuality studies, and the place of creativity and imagination in a socially critical curriculum. 